УДК 81 '373

DOI: $10.17223 / 19986645 / 53 / 7$

\title{
И.В. Тресорукова
}

\section{ПИЩЕВОЙ КОД ГРЕЧЕСКОЙ ФРАЗЕОЛОГИИ: ФИТОНИМ «ОГУРЕЦ»}

Анализируется пищевой код греческой фразеологии и один из его спеиифических фрагментов, который в качестве самостоятельного объекта ранее не исследовался. Цель статьи - рассмотреть функиионирование лексемы «огуреи» как компонента-фитонима в составе фразеологических единии на материале новогреческого языка и выявить особенности пищевого кода греческой фразеологии в целом. На основании изучения корпусов текстов и полевых исследований проведен анализ фразеологических единиц, содержащих этот фитоним, выявлен его семантические и ассочиативные аспекты в рамках рассмотрения различных сфер лексико-фразеологического поля, содержащего данную лексему, что позволяет сделать выводы об особенностях формирования греческой языковой картины мира.

Ключевые слова: фразеология, пищевой код, языковая картина мира, греческий язык, огуреи.

Фразеология имеет особую культурологическую ценность в системе любого языка [1. С. 67], являясь своеобразным хранилищем мировоззрения народа, его взглядов и идеалов. Фразеологические единицы (ФЕ) связывают язык с внеязыковой действительностью, что отражает и его аутентичность. Как пишет Ю.П. Солодуб, основу их семантики составляет фразеологический образ, в котором сохраняется национальная специфика ФЕ, так как он опирается на реалии, присущие только одной конкретной нации [2. С. 57].

С точки зрения антропоцентрического подхода к изучению языка такие образы и образные системы формируют так называемые коды культуры, которые представляют собой национально окрашенные «образные коды» [3. С. 83], выражающиеся при помощи совокупности языковых средств и регулярно воспроизводящиеся в речи. Образность в этом ключе понимается как «лексико-семантическая категория, обобщающая свойство единиц лексико-фразеологического уровня, проявляющаяся в их способности обозначить определенное явление внеязыковой деятельности (предмет, свойство, процесс, ситуацию) в ассоциативной связи с другим, нетождественным обозначаемому, явлением на основе их реального или мнимого сходства посредством метафорической внутренней формы языковой единицы» [4. 40]. В этом свете для каждой культуры типовыми выступают представления, выражаемые через образы, формируемые из первичного значения слова и его вторичной интерпретации на основании сходства обозначаемых образов, реальных или мнимых их характеристик. Например, в грече-

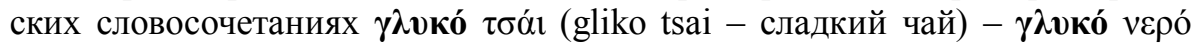




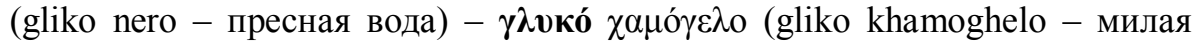
улыбка) в первом случае прилагательное $\gamma \lambda$ прямом значении, реализуя лексико-семантический вариант (ЛСВ) 'сладкий, содержащий сахар', во втором случае (преснылй) передаёт семантику 'не содержащий соли', а в третьем употреблено в метафорическом значении, реализуя ЛСВ ‘милый, вызывающий приятные ощущения'.

Основа любого культурного кода - символ как «итог смыслового развития знака в культуре», который является знаком «для устойчивого и регулярного воплощения ценностного содержания культуры, ее основных категорий и смыслов» [5. С. 211]. ФЕ в лингвокультурологии играют важную роль, так как создают особую символику окружающего мира. «Этот несколькословный языковой знак способен не только образно описывать происходящее, но и воплощать в себе устойчивые смыслы, которые являются частью семантики данного знака и извлекаются из него при употреблении фразеологизма в речи» [Там же. С. 197]. Таким образом, ФЕ наряду с другими средствами образной номинации (ср., напр., различные тропеистические средства: метафоры, сравнения и пр.) берут на себя функции по отображению и выражению материальной, духовной и языковой картины мира человека и нации в целом.

С историей человеческой цивилизации как таковой и каждого народа в отдельности неразрывно связана история еды: пищевые продукты - одна из основных движущих сил истории человечества, и вопрос питания появляется на самом раннем этапе его развития. Прием пищи неотъемлемо присутствует во всех областях межличностных и общественных отношений, с едой связаны важнейшие ритуалы и культы в человеческой жизни. «Еда - это важный фактор национального самосознания <..> и основной элемент идентичности: этнической, религиозной, социальной» [6. С. 11]. В современном обществе еда и все связанное с ней складывается в единый концепт, метафору освоения окружающего мира, и процесс современной коммуникации все больше приобретает характер глюттонический [7], т.е. связанный с потреблением пищи и поддержанием жизни.

Одним из наиболее распространенных культурных кодов является пищевой (или кулинарный) код: кулинария, гастрономия и еда в целом служат для обозначения целого комплекса различных образов (социальных, семейных, религиозных отношений, опосредованное восприятие природы и пр.), что дает возможность для подробного изучения лексикофразеологического состава этого кода. В восприятии человека «пища выступает как посредник между природой (космосом) и человеком (социумом, культурой) и вместе с тем как мерило ценности, как средство социальной коммуникации» [8. С. 60]. При этом пищевой код «находится в тесном взаимодействии с другими культурными кодами» [9. С. 211], в том числе и с анималистическим, включающим фитонимический код.

Одним из элементов формирования пищевого кода являются названия растений, или фитонимы, составляющие значительную часть греческого пищевого кода. В буквальном значении они представляют собой опреде- 
ленные ботанические реалии и уже в метафорическом смысле выступают в качестве воплощения какого-либо явления или свойства. Как пишет Н.Д. Петрова [10. С. 29], символика растений одна из самых древних и в основе ее формирования лежит распад мифологического мышления, тесно связанного с обожествлением природных реалий, и сравнение, которое человек проводит с предметами и явлениями окружающей действительности. В результате такого сравнения создается символический код природных явлений, что способствует формированию концептуальной картины мира, а символика растений приводит к появлению ботанических символов, или фитонимов.

С точки зрения семантической символики фитонимы могут быть разделены на узуальные и окказиональные. Узуальные (или константные) образовались на ранней стадии формирования человеческого сознания и доступны пониманию разных народов и национальностей. Окказиональные представляют собой отражение свойств и качеств, которые приписывает фитонимам человек [Там же]. Узуальным символам присущи постоянство и стойкость признака, а окказиональные символы, обладая динамическим характером символики, сужают или расширяют сферу своего применения, постепенно теряя ассоциативные связи [Там же]. При этом у каждого народа может быть своя окказиональная символизация [11. С. 132], и это связано с различным восприятием окружающего мира и разнообразием культур. Различные фитонимы формируют так называемое образное лексико-фразеологическое поле, где каждая лексема фигурирует в различных значениях, которые объединяются на основании «единства исходного мотивирующего образа» [8. С. 208].

В греческой фразеологии фитонимическая тематика развита весьма ши-

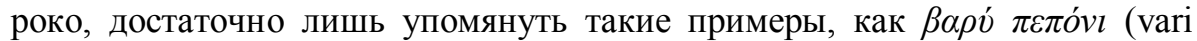
peponi) букв. «тяжелая дыня», метафорически (мтф.) «насупившийся (че-

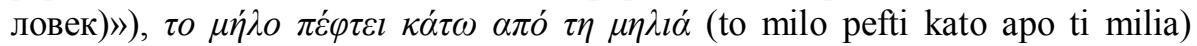
(букв. «яблочко падает под яблоню», мтф. «они очень похожи, они род-

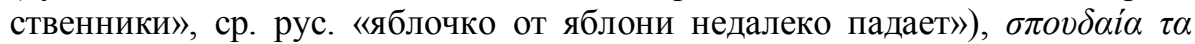
$\lambda \dot{\alpha} \chi \alpha v \alpha$ (spoudea ta lakhana) (букв. «важная капуста», мтф. «что за чепуху ты несешь») и т.п. Фитонимы весьма разнообразны и отражают различные функции, используясь как константные или окказиональные символы, передают все богатство менталитета греческого народа.

Обращаясь к такому элементу пищевого кода, как фитоним «огурец», следует отметить, что эта лексема существует в лексическом поле греческой нации с древних времен. При этом наименование огурца в древнегреческом языке архаической и классической эпохи первоначально не имеет

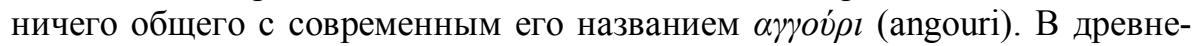
греческих текстах этот овощ называется словом бlкvós (sikios), которое употребляется в сочетании со словом $\pi \dot{\varepsilon} \pi \omega v$ (pepon), что вполне могло означать любой овощ из разряда тыквенных - дыню, кабачок и пр. На основании сохранившихся упоминаний огурца в древнегреческих текстах (согласно анализу, проведенному по базе TLG [12]) этот фитоним сразу же вос- 
принимается как продукт питания и встречается или в описаниях застолья (ср., напр., Аристофан, фрагменты комедий (4 упоминания) Афиней «Пир мудрецов» (19 упоминаний) и пр.) или же в трактатах медицинского содержания Галена, Эвсебия и пр. Весьма часто также подчеркивается качество этого овоща как содержащего семена: ср., напр., у Гесихия - $\mu \dot{\gamma} \alpha \varsigma$ бıкvó

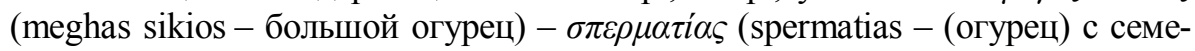
нами) (Hesychius Lexicogr., Lexicon $(\Pi-\Omega)$ (4085: 003)) или же не содержа-

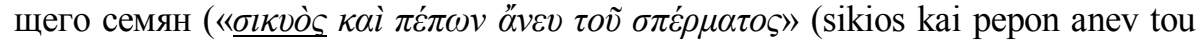
spermatos) (огурец и дыня без семян), Phaenias Phil., Fragmenta 46, 2). Огурец в древнегреческих текстах (в частности, в текстах медицинского характера, cp., напр., трактат II в. н.э. «De rebus boni malique suci», написанный знаменитым римским врачом Галеном) воспринимается как освежающий овощ, который плохо переваривается и может вызвать расстройство желудка.

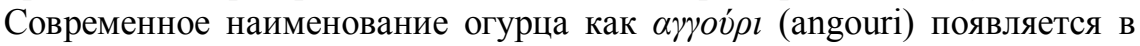
медицинских трактатах II в. н. э. и перечисляется среди овощей в различных рецептах (Anonymi Medici Med., De urinis in febribus 2, 323, 13:

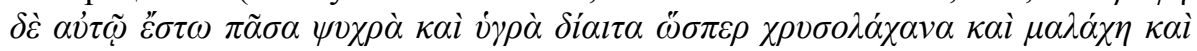

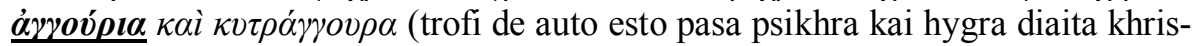
olakhana kai malakhe kai angouria kai kitrangoura) (а питанием же ему следует <выбрать> любую холодную и влажную диету, как, например, лебеду, мальву, огурцы и цуккини $\left.\left.{ }^{1}\right)\right)$. Псевдо-Гиппократ в медицинском трактате

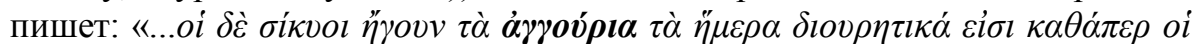

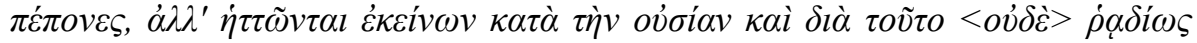
$\delta \iota \alpha \varphi \theta \varepsilon i \rho o v \tau \alpha l$ \&́v $\gamma \alpha \sigma \tau \rho i$ (oi de sikioi egoun ta angouria ta hemera diouretika eisi kathaper oi pepones all'hettontai ekeinon kata ten ousian kai dia touto <oude> radios diaftheirontai en gastri) (а огурцы, то есть окультуренные огурцы, являются мочегонными, как и дыня, но по сути более действенны, поэтому быстрее перевариваются в желудке)» (Pseudo-Hippocrates Med., Пєрі̀ $\delta 1 \alpha \varphi о \rho \tilde{\alpha} \varsigma \tau \rho о \varphi \tilde{\omega} v \pi \rho o ̀ \varsigma ~ П \tau о \lambda \varepsilon \mu \alpha \tilde{o} \nu 491,19)$, при этом в самых авторитетных современных древнегреческо-английских словарях «A Greek-English Lexicon» [13] или «A Patristic Greek Lexicon» [14] это слово не встречается,

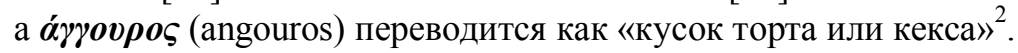

В восприятии носителя современного греческого языка огурец обладает предсказуемыми ассоциациями, и прежде всего является эвфемистической заменой фаллоса. Сложно сказать, когда именно во фразеологическом лексиконе огурец стал выполнять эту специфическую функцию, так как в Тезаурусе греческого языка нам не удалось найти соответствующих фраг-

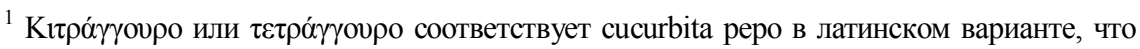
согласно современной терминологии соответствует кабачку-цуккини или же незрелой тыкве. Мы осмеливаемся предложить вариант перевода «цуккини», так как этот овощ наиболее близок по форме к огурцу. При «этимологическом», т.е. поморфемном переводе этот овощ можно интрепретировать как «лимонный огурец».

${ }^{2}$ Согласно этимологии, приводимой в этимологическом словаре новогреческого языка Г. Бабиньотиса [15], современное название огурца происходит от арабского agur и впоследствии полностью замещает древнегреческий термин.
} 
ментов с метафорическим значением. В словаре средневекового греческого

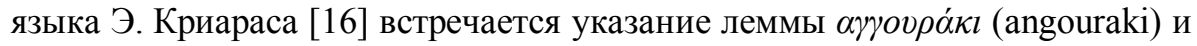
приводится как метафорическое значение «мужской член», при этом при-

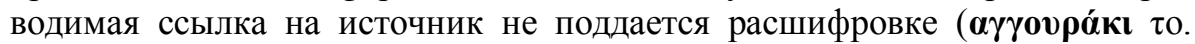

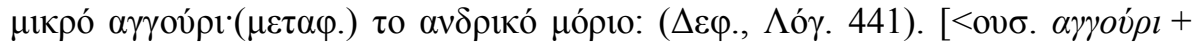

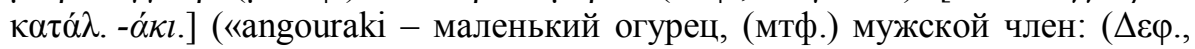

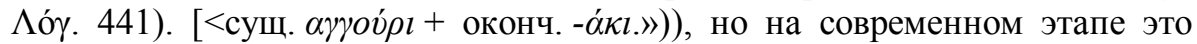
замещение весьма распространено: как пишет Эвангелос Папазахариу, огурец имеет форму, весьма напоминающую форму мужского полового органа [17], что позволяет денотату (овощу, названному фитонимической лексемой, обозначающей овощную культуру) эвфемистически подменять собой мужской половой орган. Нельзя исключить также возможность восприятия огурца как овоща, содержащего большое количество семян

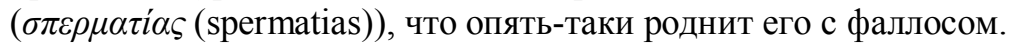

При анализе корпуса новогреческих текстов ЕӨЕГ и вычленении вариантов ФЕ, включающих лексему огурец, выявлено 14 наиболее употребитель-

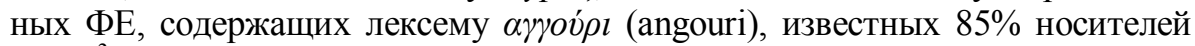
языка ${ }^{3}$, при этом оставшиеся $15 \%$ респондентов не знали предлагаемых фразеологизмов или предлагали свои варианты приводимых $\Phi \mathrm{E}^{4}$.

Среди скомпонованной группы ФЕ есть практически все категории фразеологизмов: и идиоматические, и устойчивые выражения, и паремии, и речевые формулы (классификация ФЕ проводится по теории Баранова Добровольского [18. С. 44]). Наибольшее количество приходится на долю идиоматических выражений (5 из 14), затем следуют устойчивые выражения (3 из 14), 3 паремии, 2 речевые формулы и 1 метафорический дериват.

При анализе семантики фитонима огурец в различных ФЕ прежде всего выявляются ФЕ, где огурец интерпретируется непосредственно как фалли-

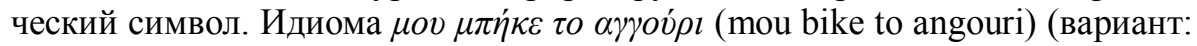

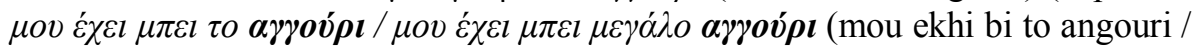
to megalo angouri)) дословно означает «в меня вошел огурец» (вариант: «в меня уже вошел огурец / большой огурец») (как правило, говорящий уточ-

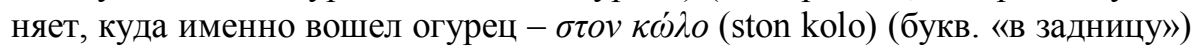
[19]) и характеризует трудности, с которыми пришлось столкнуться человеку, причем это выражение почти всегда сопровождается определенной обсценной жестикуляцией для усиления значения ФЕ.

\footnotetext{
${ }^{3}$ Анализ был произведен путем опроса различных носителей языка, выборка была сделана при сотрудничестве с Лабораторией греческого языка Университета им. Демокрита (Фракия, Греция), возрастной состав участников от 20 до 50 лет, всего в опросе приняли участие 253 человека, которым был предложен специально составленный для этой цели опросник, где содержались представленные в данной статье ФЕ.

${ }^{4} 85 \%$ респонедентов опознали ФЕ, которые в результате можно отнести к узуальным, оставшиеся 15\% респондентов выявили окказиональные ФЕ. Речь в данном случае идет о респондентах, являющихся носителями греческого языка, т.е. и узуальные, и окказиональные ФЕ формируют греческую языковую картину мира (ЯКМ).
} 
Среди речевых формул с лексемой огуреи весьма примечательной явля-

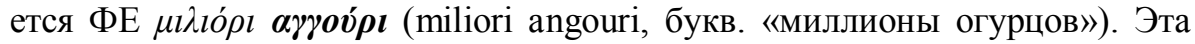
ФЕ ведет свое происхождение из рекламы макарон Misco, где итальянец

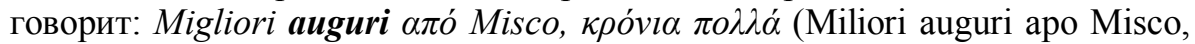
kronia polla) (букв. «Всего вам хорошего от компании Миско, с праздни-

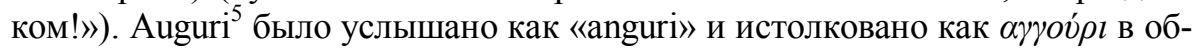
разе фаллического символа, после чего эта речевая формула вошла в язык с отрицательными коннотациями и стала означать большие неприятности и сложности, причем негативность значения передается также при помощи интонации и соответствующей жестикуляции [19]: МІИІОРІ АГГОУРІ ( $\mu \alpha$

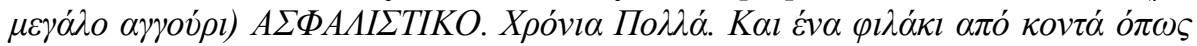

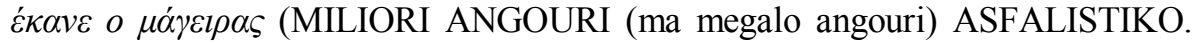
Khronia polla. Ke ena filaki apo konda opos ekane o maghiras) («ОГРОМНАЯ ПРОБЛЕМА (букв. «БОЛЬШОЙ ОГУРЕЦ») (ну очень большая проблема (букв. «ну очень большой огурец»)) - СТРАХОВОЙ ВОПРОС. С праздником. Нежно целую вас по примеру повара <из рекламы>»).

К эвфемистическим ФЕ, где огурец заменяет собой мужской половой

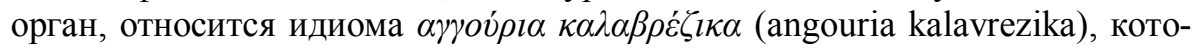
рая по одной из версий, предлагаемых Никосом Сарантакосом, является

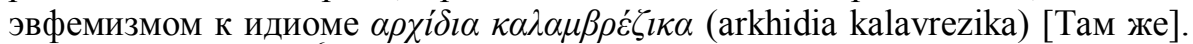
Эпитет $\kappa \alpha \lambda \alpha \beta \rho \varepsilon ́ \zeta \imath \kappa \alpha^{6}$ отсылает нас к чему-то качественному, в то время как существительное $\alpha \rho \chi i \delta l \alpha$ («яйца», бран.) обозначает нечто, не имеющее

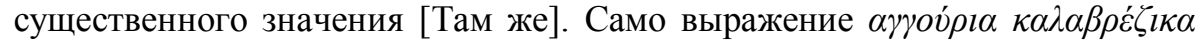
(aggouria kalavrezika, букв. «калабрийские огурцы», мтф. «черт знает что такое», «не пойми что») употребляется для обозначения пренебрежительного отношения говорящего к предмету, причем зачастую выражение

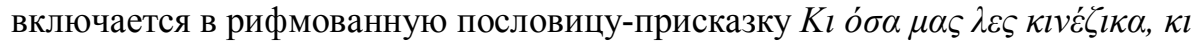

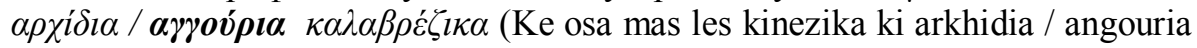
kalavrezika) (букв. «И все, что ты говоришь, - китайская грамота, и яйца /

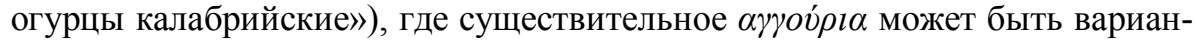
том и чередоваться с существительным $\alpha \rho \chi i \delta i \alpha$.

Фитоним $\alpha \gamma \gamma o v ́ \rho \imath$ формирует еще одну группу ФЕ, где эта лексема используется применительно к внешности человека. Идиома $\pi \varepsilon \rho \pi \alpha \tau \dot{\alpha} \omega \sigma \alpha \nu$

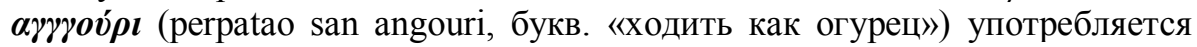

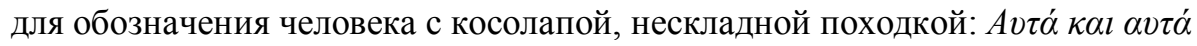

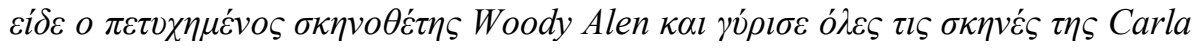

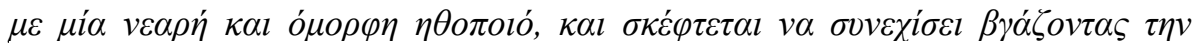

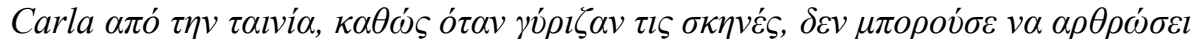

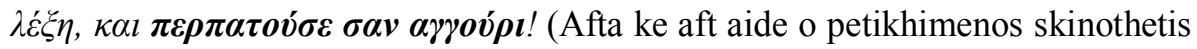

\footnotetext{
${ }^{5}$ Авгурами назывались жрецы, гадавшие по полету птиц в Древнем Риме.

6 Это прилагательное нам не удалось обнаружить в существующих толковых словарях греческого языка, но этимологически оно явно происходит от названия итальянского города Калабрия, что позволяет буквально переводить эту лексему как «калабрийский». Безусловно, в самой ФЕ это прилагательное не имеет никакого отношения к конкретному городу и в греческом языке встречается только в составе данной $Ф Е$.
} 
Woody Alen ke ghirise oles tis skines tis Carla me mia meari ke omorfi ithopio ke skeftete na sinekhisi vgazontas tin Carla apo tin tenia, kathos otan ghirisan tis skines, den mporouse na arthrosi leksi, ke perpatouse san angouri) («Вот и увидел это все успешный режиссер Вуди Аллен, и снял все сцены Карлы с молодой и красивой актрисой, и собирается так и продолжать, убрав Карлу из фильма, так как во время съемок она ни слова не могла произнести и ходила враскоряку (букв. «как огурец»)»).

Необычным является происхождение ещё одной новогреческой речевой

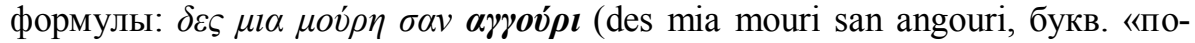
смотри на морду как огурец»). Она представляет собой фразу из стихотворения-дразнилки, описывающего уродливого человека:

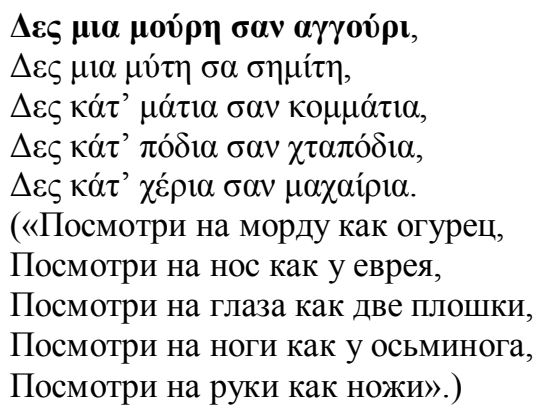

Обычно в разговоре употребляется только самая первая строка этого

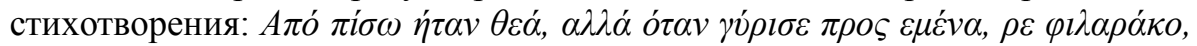

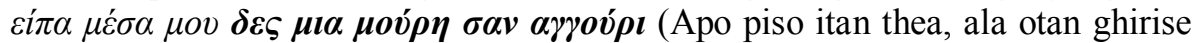
pros emena, re filarako, ipa mesa mou des mia mouri san angouri) («Сзади она была просто богиней, но когда повернулась, дружище, я сказал себе: «Глянь-ка на рожу как огурец»).

Следует отметить, что в отличие от греческого в русском языке лексема огуреи и её диминутив огурчик при описании внешности, как правило, употребляются для обозначения привлекательности человека (ср., напр., «он бодр как огурчик» или «встал утром как огурец, бодр и свеж»), в то время как в греческом фитонимы в описании личности всегда имеют отрицательные коннотации (напр., см. выше $\beta \alpha \rho v ́ \pi \varepsilon \pi o ́ v \imath)$.

К сфере «внешность и части тела» относится также пословица с лексемой

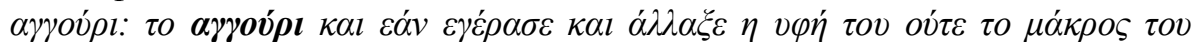

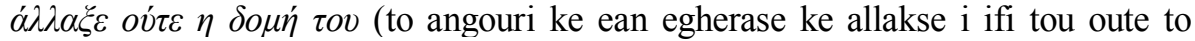
makros tou allakse oute i domi tou) («Огурец хоть и состарился и изменил свой облик, у него ни длина не изменилась, ни структура»), вариант к основной

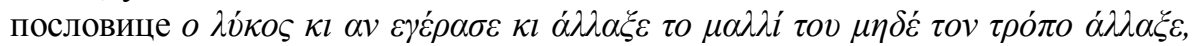

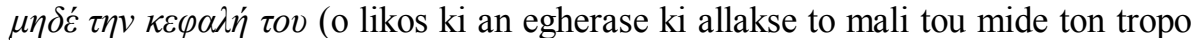
allakse mide tin kefali tou) («Волк хоть и состарился, и шерсть у него цвет изменила, у него ни привычки, ни разум не сменились»). По всей видимости, эта пословица является своеобразным неологизмом, так как в результате проведенного опроса респондентов установленоо, что данная паремия упо- 
требляется в основном в молодежной среде, появившись в активном разговорном лексиконе лишь в конце $\mathrm{XX}$ в. [21].

К группе ФЕ, связанной с описанием внешности, следует отнести и про-

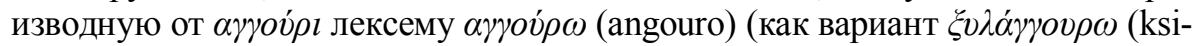
langouro) (букв. «дикий огурец»)), являющуюся метафорическим дериватом и употребляемую исключительно в форме единственного числа. Этот дериват не имеет парадигмы склонения и используется только для обозначения очень высокой, нескладной и некрасивой женщины.

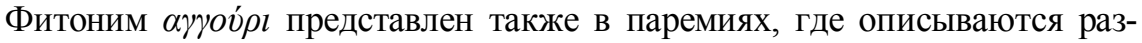
личные жизненные ситуации. Так, например, пословица $\eta \zeta \omega \eta \dot{~ \varepsilon i v a l ~ a y g o v ́ p ~}$

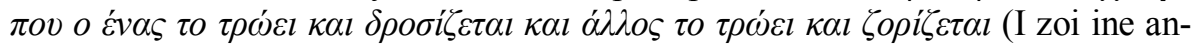
gouri pou o enas to troi ke drosizete ke allos to troi ke zorizete) (букв. «Жизнь как огурец: один его ест для свежести, а второй ест и мучается») употребляется для обозначения оптимистов и пессимистов; в русском языке этой пословице может соответствовать изречение о жизни, уподобляемой наполовину полному или пустому стакану. Синонимом к этой пословице, как указывает Н. Сарантакос [19], является паремия $H \zeta \omega \eta \dot{~ \varepsilon i v \alpha l ~ \varepsilon ́ v \alpha ~ к \rho \varepsilon \mu \mu ́ ́ \delta l ~ \pi o v ~}$

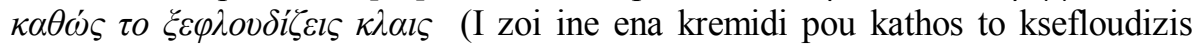
kles) (букв. «Жизнь - это лук, который ты чистишь и плачешь»).

Ещё одна пословица, содержащая фитоним огурец, $\pi \dot{v} v \varepsilon \varepsilon \mu \dot{\varepsilon} \rho \varepsilon \varsigma \tau \rho \omega \varsigma$

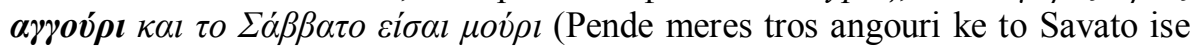
mouri) буквально означает «Пять дней ешь огурцы и в субботу прекрасно выглядишь» и употребляется для иронического обозначения молодых людей, которые стремятся попасть в число знаменитостей, но на это у них нет средств, поэтому пять дней экономии и один день развлечений становится

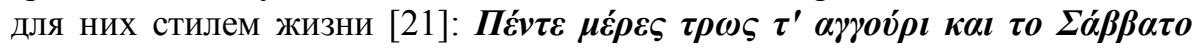

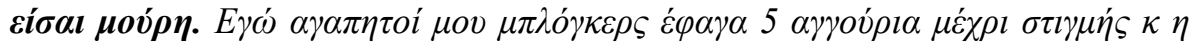

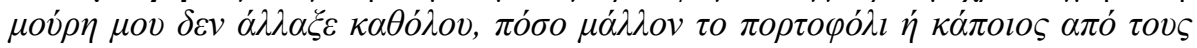

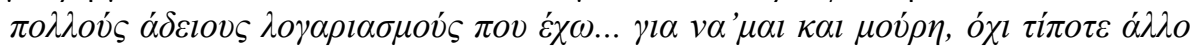
(Pende meres tros angouri ke to Savato ise mouri. Ego agapiti mou bloggers efaga 5 angouria mekhri stigmis ke i mouri mou den allakse katholou, poso malon to portofoli i kapios apo tous polous adious logariasmous pou ekho... ghia na'me ke mouri okhi tipщеe allo) («Пять дней ешь огурцы и в субботу прекрасно выглядишь. Я, дорогие мои блогеры, пока съел только 5 огурцов, и морда моя совсем не изменилась, а вот кошелек, как, впрочем, и пять пустых счетов, совсем обнищали... И все для того, чтобы и я всегонавсего мог выглядеть как человек»). Весьма часто также употребляются в

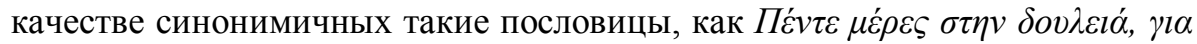

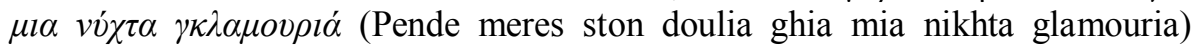

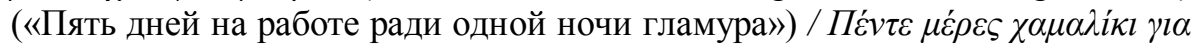

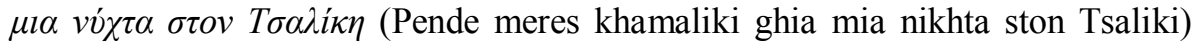
(«Пять дней как проклятый (работаю), чтобы провести одну ночь у Цали-

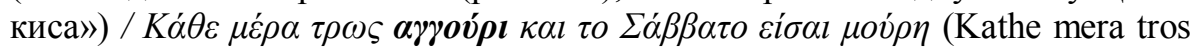
angouri ke to Savato ise mouri) («Каждый день ешь огурцы и в субботу будешь прекрасно выглядеть»). 
Кроме того, фитоним ауүои́рl формирует сферу «мировосприятие» и используется для обозначения препятствия, зачастую непреодолимого: ФЕ

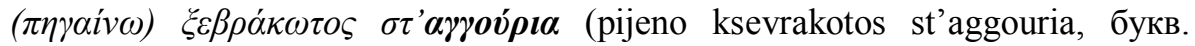
«(иду) бесштанный (= без штанов) в огурцы», мтф. «принимаюсь за дело, которое мне не по силам»), употребляется для обозначения человека, берущегося за дело, в котором он несведущ и не обладает достаточным опытом. По всей видимости, своим происхождением идиома обязана тем, что растущие на лозах огурцы, как правило, имеют колючки, и без защиты голых участков тела (рук или ног) можно оцарапаться или даже получить

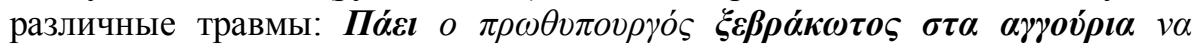

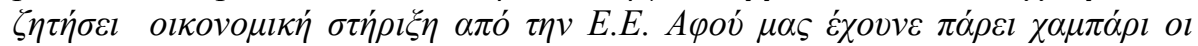

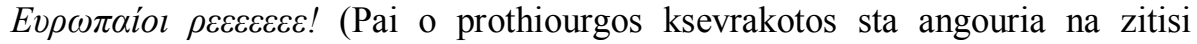
ikonomiki stiriksi apo tin EE. Afou mas ekhoune pari khambari oi Evropei reee!) («Наш премьер лезет не в свое дело (букв. «идет без штанов в огурцы») и хочет получить финансовую помощь от ЕС. Да европейцы нас уже давно раскусили!!!»). Эвфемистическим вариантом для этой ФЕ служит

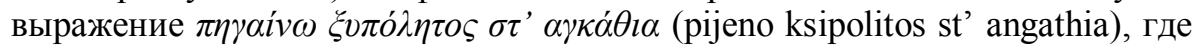

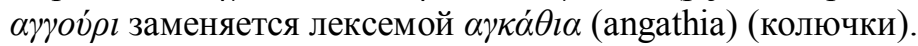

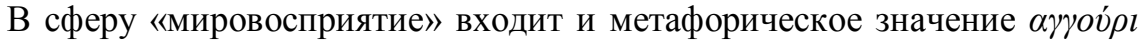
«сложное, запутанное дело» (что весьма близко к предыдущему значению «зачастую непреодолимое препятствие»): причем здесь сфера «мировоз-

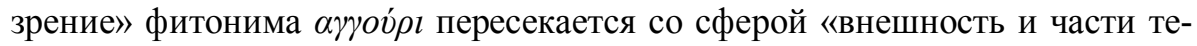

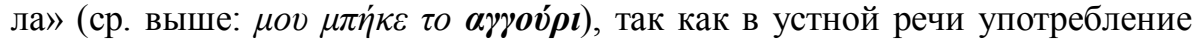
$Ф Е$ с данной лексемой может сопровождаться соответствующими обсцен-

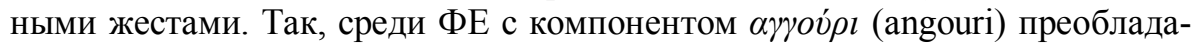
ют глагольные идиомы с главным компонентом - глаголом: sival ayjov́pt

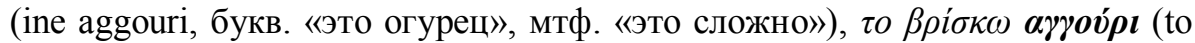
vrisko aggouri, букв. «я нахожу это огурцом», мтф. «это сложно для меня»), где огурец означает нечто сложное, непреодолимое, создающее большое

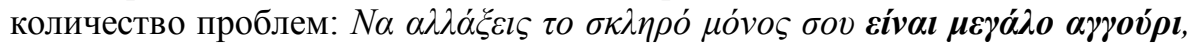

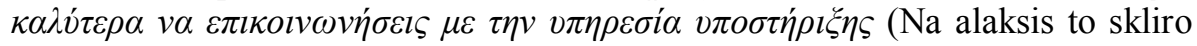
monos sou ine megalo angouri, kalitera na epikinonisis me tin omada ipostiriksis) («Самому поменять жесткий диск - это непосильная задача,

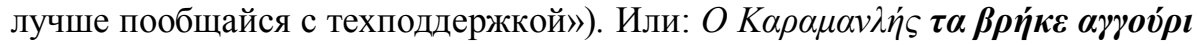
$\kappa \alpha l \tau \alpha \pi \alpha \rho \dot{\tau} \tau \eta \sigma \varepsilon$ (O Karamanlis ta vrike anguri ke ta paratise) («Караманлис счел это непосильным и все бросил»). Сразу следует отметить, что $\alpha \gamma \gamma o v ́ \rho t$ в такого рода ФЕ всегда стоит в форме единственного числа как компонент, полностью утративший свои первоначальные морфологические и семантические признаки. Синонимами к этой фразе служат такие ФЕ, как $\tau \alpha \beta$ píкผ $\mu \pi \alpha \sigma \tau o v ́ v l \alpha$ (ta vrisko bastounia, букв. «я нахожу это палками»,

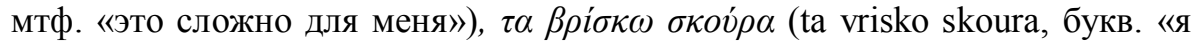
нахожу это темным», мтф. «это сложно для меня»).

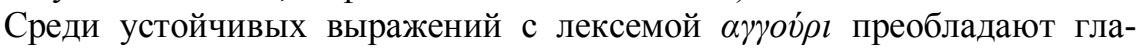
гольные ФЕ, которые используются для обозначения ненужного, непригодного к употреблению предмета и, как следствие, ненужного и напрас- 
ного действия, формируя тем самым сферу «межличностные отношения»:

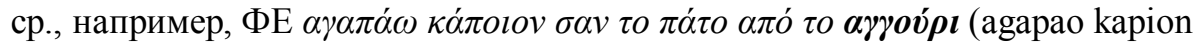
san to pato apo to angouri, букв. «любить кого-либо как «попку» от огурца»). Как пишет Н. Сарантакос [19], «попка» огурца непригодна для еды, поэтому она обозначает что-то совсем не стоящее внимания, при этом си-

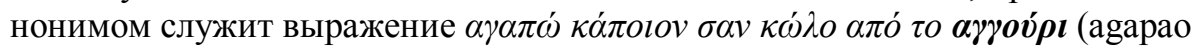
kapion san kolo apo to angouri, букв. «любить кого-либо как жопку от огурца»). Здесь часть фитонима приобретает значение ненужного, не обладающего ценностью предмета.

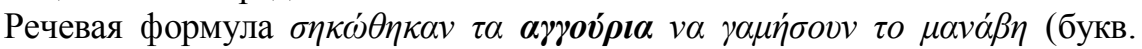
«восстали огурцы, чтобы отъе...ать зеленщика», русский коррелят «твой номер восемь, жди когда спросим» или «яйца курицу не учат») употребляется для обозначения ситуации, при которой дерзкие, но не имеющие власти люди пытаются изменить ситуацию, не обладая должным опытом и компетенцией. Здесь фитоним используется для обозначения ничтожного, незначительного человека. Эта формула считается грубо-просторечной и обычно произносится язвительно-ироническим тоном, при этом глагол и существи-

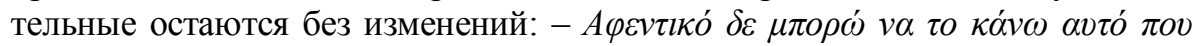

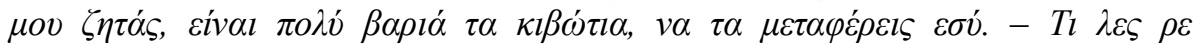

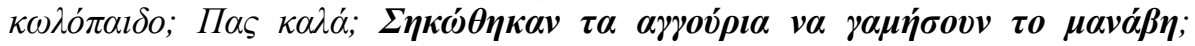

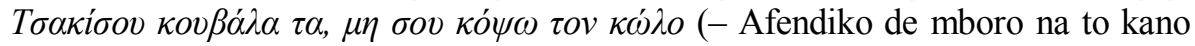
afto pou mou zitas, ine varia ta kivotia, na ta metaferis esi. - Ti les re kolopedo? Pas kala? Sikothikan ta angouria na gamisoun to manavi? Tsakisou kouvala ta, mi sou kopso ton kolo) («- Начальник, я не могу сам с этим справиться, коробки тяжелые, давай ты их сам отнесешь. - Дрянь такая, ты еще выступаешь? Нука быстро взял и оттащил, иначе я тебя сейчас отымею в зад» (букв. «Что ты говоришь, дитя задницы? С тобой не все в порядке? Поднялись огурцы, чтобы отъе..ать зеленщика? Сорвался и тащи, чтобы я тебе зад не порвал»)).

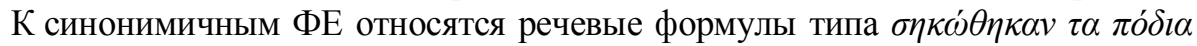

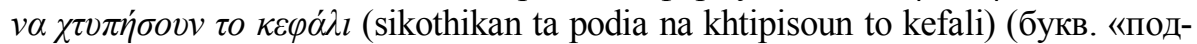

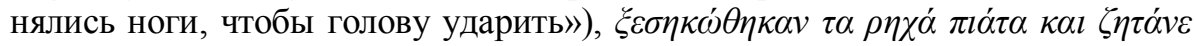
бои́ $\alpha \alpha$ (ksesikothikan ta rikha piata ke zitane soupa) (букв. «устроили восстание

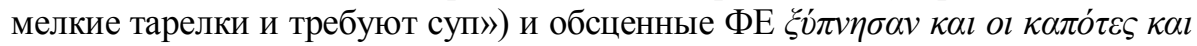

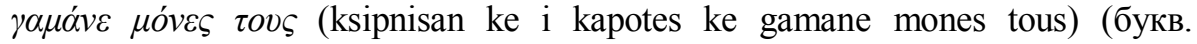

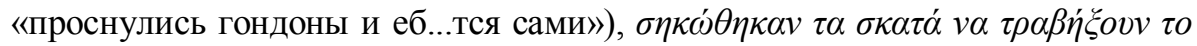

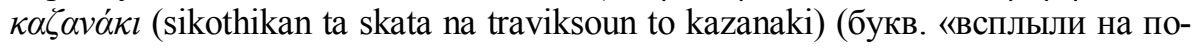

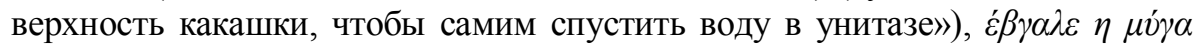

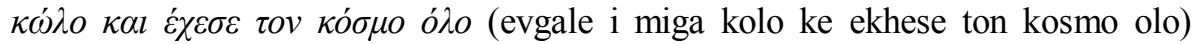

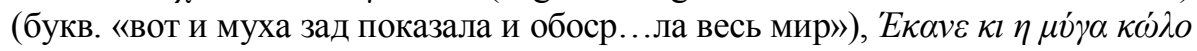

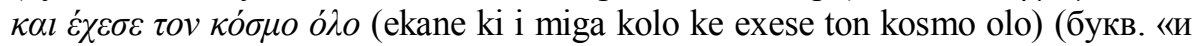
муха задницу отрастила и обоср...ла весь мир»), غ́ $\mu \alpha \theta \varepsilon v \alpha \beta \varepsilon \lambda o v l \alpha ́ \zeta \varepsilon l \kappa \alpha l ~ \gamma \alpha \mu \varepsilon i ́$

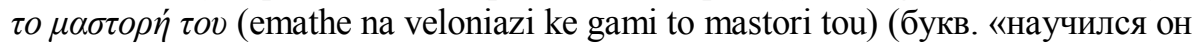
иголкой работать и теперь еб...т своего начальника»).

Таким образом, в результате проведенного анализа выявляется, что лек-

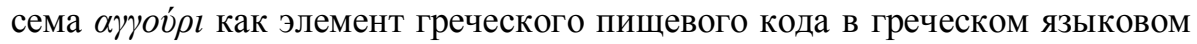


сознании существует с древних времен и воспринимается прежде всего как название продукта питания, а не растения (ср., напр., ФЕ современного

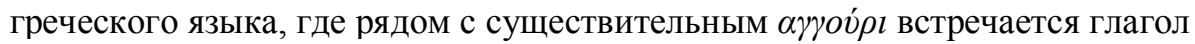
$\tau \rho \omega ́ \omega$ (troo, «есть, питаться»)). Анализ показал, что фитоним огуреu реализует в новогреческом языке богатые ассоциативные связи, которые проявляются в различных лексико-фразеологических полях (ЛФП): так, ЛФП «огурец» формирует такие понятийные сферы, как «внешность человека и части тела», «поведение», «межличностные отношения», «мировосприятие», где самым частотным становится поле «внешность и части тела» (5 ФЕ и один метафорический дериват), затем следуют «поведение» (3 ФЕ), «мировосприятие» (3 ФЕ), «межличностные отношения» (2 ФЕ). При этом в значительной мере данные фитонимы носят узуальный характер (это касается, прежде всего, сферы «внешность человека и части тела»), а окказионализмы, в свою очередь, характерны именно для греческой языковой картины мира, как это было показано выше.

\section{Лuтература}

1. Алефиренко Н.Ф. Фразеология и культура // Язык и культура: Тезисы Второй международной конференции. Киев, 1993. Ч. 1. С. 67-68.

2. Солодуб Ю.П. Контрастивная фразеология // Филологические науки. 1998. № 4. C. $57-65$.

3. Юрина Е.А. Лексико-фразеологическое поле кулинарных образов в русском и итальянском языках // Язык и культура. 2008. № 3. С. 83-93.

4. Юрина Е.А. Образность в системе лексико-семантических категорий языка // Вестник Томского государственного университета: Бюллетень оперативной научной информации. 2004. № 32. С. 25-58.

5. Ковшова М.Л. Лингвокультурологический метод во фразеологии: Коды культуры. M. : URSS, 2012.

6. Павловская A.B. Нужна ли нам наука о еде? // Еда и культура: По материалам I Международного научно-практического симпозиума «Традиционная культура в современном мире. История еды и традиции питания народов мира», 30 октября 1 ноября 2014 г. М., 2015. С. 7-4.

7. Щербинина Ю.В. Дикта(н)т еды // Нева. 2012. № 7. С. 221-230.

8. Агапкина Т.А., Толстая С.М. Пища // Славянские древности: Этнолингвистический словарь : в 5 т. / под общ. ред. Н.И. Толстого. М., 2009. Т. 4.

9. Юрина Е.А. «Пищевая метафора»: объем и границы понятия // Вестник Кемеровского государственного университета. 2015. № 3. С. 207-2011.

10. Петрова Н.Д. Лінгво-гносеологічні основи динаміки фразеологічної номінації (на матеріалі англійської фразеології живої природи) : автореф. дис. ... д-ра філол. наук. Киів, 1996.

11. Черданщева T.3. Идиоматика и культура (постановка вопроса) // Вопросы языкознания. 1996. № 1. С. 58-70.

12. Thesaurus Linguae Graecae (TLG). URL: www.tlg.uci.edu/index.prev.php

13. Liddell H.G., Scott R. A Greek-English Lexicon. 1996.

14. Lampe G.W.H. A Patristic Greek lexicon. Oxford : Oxford Clarendon Press, 1961.

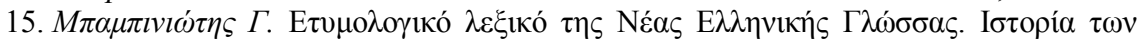

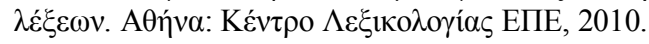

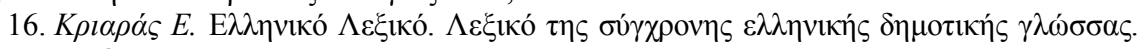

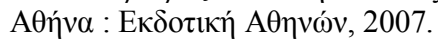




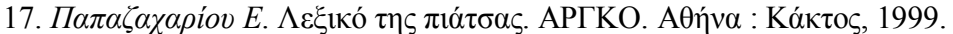

18. Баранов А., Добровольский Д. Основы фразеологии. М. : Флинта, 2013.

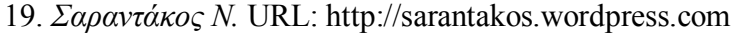

\section{THE FOOD CODE OF GREEK PHRASEOLOGY: THE PHYTONYM "CUCUMBER"}

Vestnik Tomskogo gosudarstvennogo universiteta. Filologiya - Tomsk State University Journal of Philology. 2018. 53. 98-110. DOI: 10.17223/19986645/53/7

Irina V. Tresorukova, Lomonosov Moscow State University (Moscow, Russian Federation). E-mail: itresir@mail.ru

Keywords: phraseology, food code, language picture of the world, Greek language, cucumber.

The article deals with the problem of the formation of the food code in Greek phraseology on the basis of the analysis of one of its components - the phytonym "cucumber". The food code is one of the components of the cultural code, which forms images and figurative systems expressed by the combination of linguistic means, and it is regularly reproduced in speech. Phraseological units (PU) are used as the material for research, for they play an important role in linguoculturology, as they create a special symbolism of the surrounding world. Among the other meanings of figurative nomination (e.g. various tropeic meanings like metaphors, comparisons, etc.), PU take on the functions of imaging and expressing the material, spiritual and language picture of the world of man and the nation as a whole.

One of the most common cultural codes is the so-called food code, for the cooking, the gastronomy and food in general help us to designate a whole complex of different images (social, family, religious relations, perception of nature, etc.), which gives us a possibility for a detailed study of the lexico-phraseological composition of this code.

From the point of view of semantic symbolism, phytonyms can be divided into constant and occasional. Constant ones were formed at the early stage of the formation of human consciousness and they are accessible to the understanding of different peoples and nationalities. Occasional phytonyms represent a reflection of the properties and qualities that the person attributes to phytonyms. Conventional symbols are inherent in the constancy and persistence of the feature, while occasional symbols, because of the dynamic character of their symbolism, narrow or broaden the field of their application, gradually losing associative connections. Different phytonyms form so-called figurative lexical-phraseological fields, where each lexeme appears in various meanings either occasionally or conventionally.

The relevance and originality of this article are that for the moment no one has been engaged in the study of the food code on the material of Greek phraseology in Russian linguistics, and the material, collected as a result of studying the corpus of texts of the Greek language and of field research made directly with speakers, gives us the possibility for making conclusions, which describe another view on the Greek language picture of the world.

As a result of the analysis, it has been identified that the phytonym "cucumber" as an element of the Greek food code and the component of the PU in the Greek linguistic consciousness has existed since ancient times, and is perceived primarily as the name of a food product, and not a plant. The phytonym "cucumber" realizes rich associative connections in the Greek language, which manifest themselves in various lexical-phraseological fields, such as "appearance of a person and body parts" (the most frequent, 5 PU and one metaphorical derivative), "behavior" (3 PU), "world perception" (3 PU), "interpersonal relations" ( 2 PU). At the same time, to a considerable extent, these PU have a conventional nature (we discern it primarily in the field "appearance of a person and a part of the body"), while occasional PU are only characteristic for the Greek language picture of the world. 


\section{References}

1. Alefirenko, N.F. (1993) [Phraseology and culture]. Yazyk $i$ kul'tura [Language and Culture]. Abstracts of the 2nd international conference. Pt. 1. Kiev: [s.n.]. pp. 67-68. (In Russian).

2. Solodub, Yu.P. (1998) Kontrastivnaya frazeologiya [Contrastive phraseology]. Filologicheskie nauki. 4. pp. 57-65.

3. Yurina, E.A. (2008) Leksiko-frazeologicheskoe pole kulinarnykh obrazov v russkom i ital'yanskom yazykakh [Lexico-phraseological field of culinary images in Russian and Italian languages]. Yazyk i kul'tura - Language and Culture. 3. pp. 83-93.

4. Yurina, E.A. (2004) Obraznost' v sisteme leksiko-semanticheskikh kategoriy yazyka [Figurativeness in the system of lexico-semantic categories of language]. Vestnik Tomskogo gosudarstvennogo universiteta: Byulleten' operativnoy nauchnoy informatsii. 32. pp. 25-58.

5. Kovshova, M.L. (2012) Lingvokul'turologicheskiy metod vo frazeologii: Kody kul'tury [Linguistic and cultural method in phraseology: Codes of culture]. Moscow: URSS.

6. Pavlovskaya, A.V. (2015) Nuzhna li nam nauka o ede? [Do we need a science of food?]. In: Eda i kul'tura: Po materialam I Mezhdunarodnogo nauchno-prakticheskogo simpoziuma "Traditsionnaya kul'tura $v$ sovremennom mire. Istoriya edy i traditsii pitaniya narodov mira", 30 oktyabrya - 1 noyabrya 2014 g. [Food and Culture: Based on the materials of the first international scientific and practical symposium "Traditional culture in the modern world. The history of food and traditions of nutrition of the peoples of the world", October 30 - November 1, 2014]. Moscow: Moscow State University. pp. 7-4.

7. Shcherbinina, Yu.V. (2012) Dikta(n)t edy [Dictat-e(ion) of food]. Neva. 7. pp. 221-230.

8. Agapkina, T.A. \& Tolstaya, S.M. (2009) Pishcha [Food]. In: Tolstoy, N.I. (ed.) Slavyanskie drevnosti: Etnolingvisticheskiy slovar': $v 5 t$. [Slavic antiquities: Ethnolinguistic dictionary: in 5 vols]. Vol. 4. Moscow: Rukopisnye pamyatniki drevney Rusi

9. Yurina, E.A. (2015) "Food metaphor": the scope and limits of the concept. Vestnik Kemerovskogo gosudarstvennogo universiteta - Bulletin of Kemerovo State University. 3. pp. 207-2011. (In Russian).

10. Petrova, N.D. (1996) Lingvo-gnoseologichni osnovi dinamiki frazeologichnoi nominatsiï (na materiali angliys'koï frazeologï zhivoï prirodi) [Linguo-gnoseological basis of the dynamism of phraseological nominations (on the material of the English phraseology on nature)]. Abstract of Philology Dr. Diss. Kiev.

11. Cherdantseva, T.Z. (1996) Idiomatika i kul'tura (postanovka voprosa) [Idiomatics and culture (to the problem setting)]. Voprosy yazykoznaniya. 1. pp. 58-70.

12. Thesaurus Linguae Graecae (TLG). [Online] Available from: www.tlg.uci.edu/index.prev.php.

13. Liddell, H.G. \& Scott, R. (1996) A Greek-English Lexicon. Clarendon Press.

14. Lampe, G.W.H. (1961) A Patristic Greek lexicon. Oxford: Oxford Clarendon Press.

15. Babiniotis, G. (2010) Etymological Dictionary of the Modern Greek Language. History of words. Athens: Center of Lexicology Ltd. (In Greek).

16. Kriaras, E. (2007) Greek Dictionary. Dictionary of modern Greek language. Athens: Editorial Athens. (In Greek).

17. Papazachariou, E. (1999) Dictionary of Slang. Athens: Cactus. (In Greek).

18. Baranov, A. \& Dobrovol'skiy, D. (2013) Osnovy frazeologii [Fundamentals of phraseology]. Moscow: Flinta.

19. Sarantakos. (n.d.) [Online] Available from: http://sarantakos.wordpress.com. (In Greek). 